\title{
Electrical Control of Escherichia coli Growth Measured with Simultaneous Modulation and Imaging
}

\author{
Xu Han, MS, Bradley R. Foster, and Christine K. Payne, PhD
}

\begin{abstract}
Background: The use of electricity to mediate bacterial growth is unique in providing spatial control, but requires a more detailed understanding.

Methods: We use two gold wires on a glass coverslip with an overlayer of agar to image Escherichia coli cells with brightfield and fluorescence microscopy while simultaneously applying a voltage. Cells outside of the wires provide a control population to measure cell growth as a function of voltage, rather than any difference in culture conditions or growth phase.

Results: An applied voltage suppresses the fraction of $E$. coli undergoing elongation and division with recovery to control values when the voltage is removed. Depolarization is observed over the same voltage range suggesting a membrane potential-mediated response.

Conclusions: Our experiments identify and use subcytotoxic voltages to measure differences in the fraction of $E$. coli cells elongating and dividing as a function of applied voltage. It is hoped that this research will inform the developing field of bacterial electrophysiology.
\end{abstract}

Keywords: bacterial electrophysiology, bioelectricity, cell elongation, cell division

\section{Introduction}

$\mathbf{T}$ HE ABILITY TO CONTROL THE GROWTH of bacteria has far-ranging implications for human health and disease. Although a range of antibiotics and ionophores offer finely tuned chemical pathways to limit bacterial growth, these are all solution-phase agents that lack spatial control. In comparison, the use of electricity provides an orthogonal approach with the added ability to localize an applied voltage to a specific subset of cells.

Much previous study has used electricity to electroporate bacteria, with the goal of sterilization or transformation. ${ }^{1-8}$ We instead describe the use of an applied voltage to control and study bacterial growth, contributing to the growing field of bacterial electrophysiology. ${ }^{9,10}$ Although there has been much recent excitement in the use of the mammalian cell resting membrane potential for regenerative medicine $e^{11,12}$ and cancer, ${ }^{12-15}$ there are only a few examples of mechanistic, rather than antibacterial, studies and uses of bacterial electrophysiology. These examples include a recent study showing that the sporulation of Baciillus subtilis is controlled by bacterial electrical signaling, ${ }^{16}$ and that changes to the bacterial resting membrane potential can be used to screen for sensitivity to antibacterial agents. ${ }^{17}$ In addition, a recent study has shown that a conducting polymer wire can be used to control the membrane potential of individual Escherichia coli ${ }^{18}$ illustrating the use of the spatial control provided by an electrical input. Earlier study examined the curved growth of E. coli, Enterobacter cloacae, and B. subtilis as a function of electric field. ${ }^{19}$ These previous experiments motivate the need for fundamental experiments and tools to examine bacterial growth as a function of applied voltage. Previous studies of bacterial cell division identified the resting membrane potential as a key parameter in controlling the localization of proteins necessary for cell division. ${ }^{20}$ Similarly, membrane potential has been linked to cell wall synthesis mediated by turgor pressure and membrane tension. ${ }^{21,22}$ This combination of previous study suggests that an applied electric field could be used to control bacterial growth directly.

Our experiments identify and use subcytotoxic voltages to characterize cell growth at a voltage range between normal cell growth and cell death. This range of voltages allows us to examine difference in the fraction of cells undergoing elongation and division, voltage-dependent suppression of cell growth, and the underlying mechanism of this voltagedependent response. These experiments are enabled by a simple device consisting of two gold wires on a glass coverslip with an overlayer of agar that allows us to image cells in real time, with both brightfield and fluorescence microscopy, while simultaneously applying a voltage. Cells outside

Department of Mechanical Engineering and Materials Science, Duke University, Durham, North Carolina, USA. 
of the wires provide a control population that allows us to measure cell growth as a function of voltage, rather than any difference in culture conditions or growth phase. ${ }^{23-26}$ Overall, we have identified a voltage range at which cell elongation and division is suppressed, but recovers to normal levels with removal of the voltage. This change in cell growth is accompanied by the depolarization of the cells. It is hoped that this identification of a voltage range that slows, but does not damage cells, will be useful for future studies within the bacterial electrophysiology community.

\section{Materials and Methods}

\section{Device configuration for combined modulation and imaging}

Two gold wires $(0.2 \mathrm{~mm}$ diameter, $\sim 40 \mathrm{~mm}$ length, \#10195; Alfa Aesar, Haverhill, MA) were placed in parallel, by hand, with $1 \mathrm{~mm}$ spacing, on a glass coverslip (\#1254418; Thermo Fisher Scientific, Waltham, MA). A section of a polypropylene conical tube $(17 \mathrm{~mm}$ diameter, $\sim 40 \mathrm{~mm}$ length, \#352096; Corning, Corning, NY) was placed over the wires to form a chamber for the cells. Epoxy was used to immobilize the tube and prevent leakage of medium. In the fully assembled device, we measure $1.5 \%$ variation in the spacing of the wires and $12 \%$ device-to-device variation (three devices, three points on each device). The gold wire electrodes were connected to a function generator (33120A; Agilent, Santa Clara, CA) by copper tape (\#102091-345; VWR, Radnor, PA). Unless otherwise noted, experiments used a biphasic square wave with a frequency of $0.5 \mathrm{~Hz}$. The voltage used for each experiment is noted in the text. Immobilization of the cells in the device is described as follows. An image of the device is shown in Figure 1.

\section{Cell culture, immobilization, and measurement}

E. coli (initially cultured from One Shot TOP10, \#C404010; Invitrogen, Carlsbad, CA) were cultured in LuriaBertani (LB) broth (\#12795027; Thermo Fisher) overnight at $37^{\circ} \mathrm{C}$ in a shaking incubator (ISF4-X, Birsfelden, Switzerland) at $150 \mathrm{rpm}$. Cells were diluted 1:100 and seeded inside the chamber of the device, mixed thoroughly, and allowed to settle. After settling, the LB broth was replaced with $0.8 \%$ LB agar (\#22700025; Thermo Fisher) in phosphate buffered sa- line (PBS, \#21300025; Thermo Fisher) at $37^{\circ} \mathrm{C}$, which then solidified ( $\sim 20 \mathrm{~min})$ at room temperature $(\mathrm{RT})$. For imaging, the device is placed on a microscope objective, which is heated to $37^{\circ} \mathrm{C}$ with an objective heater (\#150803; Bioptechs, Butler, PA) for 30 min before placing the device on it. Heat tape, preheated and calibrated to $37^{\circ} \mathrm{C}$, is wrapped along the polypropylene tube of the device to provide additional temperature control. The device is allowed to equilibrate on the objective for $5 \mathrm{~min}$ before experiments, at which point the temperature of the agar pad is $34.8^{\circ} \mathrm{C}$. Cells were imaged before and after experiments and were then measured using ImageJ. ${ }^{27}$ Cell growth was measured as the fraction of cells undergoing elongation and division. Cells were denoted as elongating if the length of the cell increased by $\geq 20 \%$ during the experiment. We selected a $\geq 20 \%$ increase in cell length as the minimum change we could reliably resolve in our images. For cell growth experiments, 80-120 cells were measured for each experiment and compared with the same population of cells, on the same device, external to the electric field. For membrane potential imaging, 15 cells were measured at each time point. For both measurements, experiments were carried out in triplicate using three devices. Average and standard deviation from the three experiments are shown. $p$ values were calculated using a chi-squared test for categorical data or a two-tailed Student's $t$-test for numerical data for the comparison of two data sets. One-way analysis of variance was used for comparison of multiple numerical data sets, as noted in the text. The integrity of the cell membrane was tested with propidium iodide (PI, $500 \mathrm{nM}$, 10 min, \#P1304MP; Thermo Fisher), a cell impermeant dye that becomes fluorescent when intercalated with DNA. As a positive control for PI staining, E. coli were incubated at $100^{\circ} \mathrm{C}$ for $15 \mathrm{~min}$.

\section{Imaging changes in membrane potential}

Rhodamine 123 (\#R302; Thermo Fisher) was used to probe changes in membrane potential. Rhodamine 123 is a cell-impermeable dye that must be loaded into cells and is then released from the cell as it depolarizes, leading to a decrease in fluorescent signal. ${ }^{18,28-30}$ To load cells with Rhodamine $123, E$. coli in LB broth were pelleted $(4000 \mathrm{rpm}$, $5 \mathrm{~min}, \times 3$ ) to exchange media. Ethylenediaminetetraaceticacid (EDTA, 10 mM, \#EDS; Sigma-Aldrich, St. Louis, MO) was
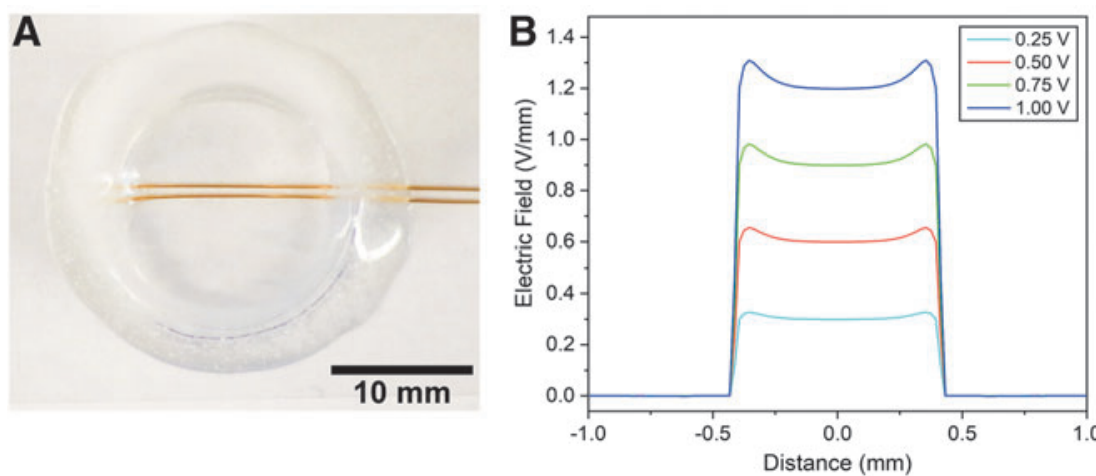

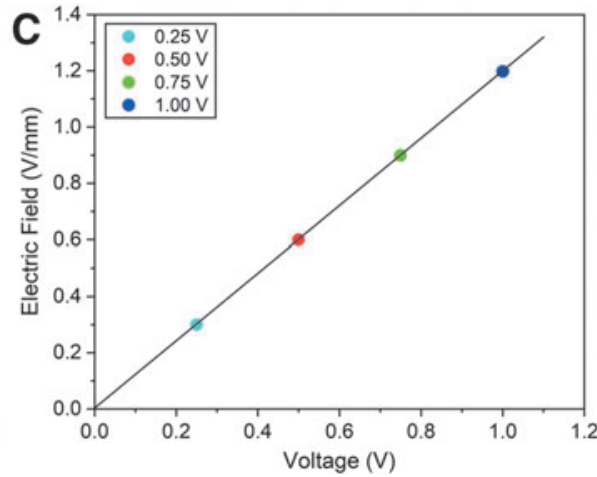

FIG. 1. Experimental configuration. (A) Photograph of the device used to image cells while applying a voltage. (B) Model of the electric field generated between the two gold wires. Cells external to the wires, where the electric field is 0 , were used as a control. (C) Electric field at the midpoint between the wires as a function of voltage. 
added to the cell pellet for a final volume of $1 \mathrm{~mL}$, vortexed, and incubated at RT for $10 \mathrm{~min}$. The EDTA chelates calcium leading to permeabilization of the bacterial cell membrane. The cell suspension was then centrifuged $(4000 \mathrm{rpm}, 5 \mathrm{~min}, \times 3)$ and washed with PBS to remove the EDTA. E. coli were then incubated with Rhodamine $123(0.2 \mu \mathrm{M}$ in LB broth, RT, $20 \mathrm{~min}$ ). Experiments, using the same immobilization method as described earlier, were carried out in the presence of Rhodamine $123(0.2 \mu \mathrm{M})$.

\section{Brightfield and fluorescence microscopy}

An advantage of our experimental setup is the ability to simultaneously apply a voltage to a subset of cells while also imaging the cells using either a brightfield or fluorescence configuration. Images were collected using an epi-fluorescence microscope (Olympus IX71, 40× objective 1.30 numerical aperture [NA] and $100 \times$ objective $1.30 \mathrm{NA}$, both oil immersion; Olympus Corporation, Tokyo, Japan) in an inverted configuration with an Electron Multiplying Charged Coupled Device camera (iXon; Andor, Belfast, Ireland). Brightfield imaging was used to monitor cell elongation and division $(40 \times$ objective). Fluorescence microscopy was used to monitor PI (Excite: $535 \mathrm{~nm}$, Emit: $617 \mathrm{~nm} ; 40 \times$, tetramethylrhodamine filter, $60 \mathrm{~ms}$ exposure) and Rhodamine 123 (Excite: $507 \mathrm{~nm}$, Emit: $529 \mathrm{~nm}, 100 \times$, fluorescein isothiocyanate filter, $60 \mathrm{~ms}$ exposure).

\section{COMSOL modeling}

COMSOL Multiphysics (COMSOL, Burlington, MA) was used to model the device and simulate the generated electric fields using the stationary electric currents module. Of specific interest was any spatial variation in electric field between the two wires. Although the voltage applied to the system is pulsatile, the relatively low frequency of the pulses $(0.25 \mathrm{~Hz}-1 \mathrm{~Hz})$ allowed use of a stationary approach to visualize the electric field felt by the cells for each discrete pulse. Each wire was modeled as a $0.2 \mathrm{~mm}$ diameter smooth cylinder placed on top of the glass side $1.0 \mathrm{~mm}$ apart. The LB agar solution was assumed to have the electrical properties of water. Cells were assumed to have the same conductivity as the surrounding media and did not affect the electric field. One wire was selected as ground, whereas the other was a voltage terminal. Material properties were selected from the COMSOL material database: Conductivities were $5.0 \times 10^{7}$ $\mathrm{S} / \mathrm{m}$ for the gold wires, $5.5 \times 10^{-6} \mathrm{~S} / \mathrm{m}$ for the LB agar solution, and $1.0 \times 10^{-14} \mathrm{~S} / \mathrm{m}$ for the glass slide. Relative permittivity was set to 1 for the gold wires, 4.2 for the glass slide, and 72 for LB agar solution. After initial testing showed uniformity in the $\mathrm{x}$-dimension, the three-dimensional geometry was simplified to two-dimensional to allow for finer analysis of the model.

\section{Results}

\section{Simultaneous modulation and imaging} of the electric field

We first designed a simple device that allows us to image single cells, with either brightfield or fluorescence microscopy, while simultaneously controlling the applied voltage with two gold wires (Fig. 1A). Cells are imaged in an inverted configuration with the coverslip placed on top of the objec- tive. Experiments described in the main text used a biphasic square wave with a frequency of $0.5 \mathrm{~Hz}$. The voltage used for each experiment is noted in the text. COMSOL modeling shows the electric field generated between the two gold wires with a linear dependence on voltage (Fig. 1B, C). An advantage of this configuration is the ability to image cells on the same coverslip, but external to the wires, serving as a control in the absence of an applied voltage. An overlayer of agar immobilizes the cells during experiments.

\section{Voltage-dependent bacteria elongation and division}

Much previous study has shown that bacteria growth is sensitive to an applied voltage. ${ }^{1-7}$ The device described earlier (Fig. 1A), provides an experimental platform to test this on a single-cell level by imaging bacteria in a brightfield or fluorescent configuration as a voltage is applied across the gold wire electrodes.

Bacteria growth was measured using two parameters; the fraction of cells undergoing elongation and division. Although cell division is a standard measure of growth, we noted that with an applied voltage many cells underwent elongation, but failed to divide, and have tracked the two parameters separately. Cells were denoted as elongated if they increased in length by $\geq 20 \%$ during the $1 \mathrm{~h}$ of observation. As a control, cell elongation is simultaneously monitored on the same device, but external to the wire electrodes at a point where no voltage is applied (Fig. 1A, B). Cell division is tracked as the number, 0,1 , or $\geq 2$ of cell divisions that occurred in the $1 \mathrm{~h}$ period. After more than two divisions, the cells become crowded and difficult to track. For each cell growth experiment, $\sim 100$ cells are analyzed. Average and standard deviation are shown for three separate experiments carried out with three separate devices.

In the absence of an applied voltage, individual cells are observed to elongate and divide over the course of $1 \mathrm{~h}$ (Fig. 2A, B). At relatively low voltages $(\leq 0.75 \mathrm{~V})$, the percentage of cells that elongate (at $0.75 \mathrm{~V}=99.5 \pm 3.2 \%$, normalized to the control cells external to the wires) are nearly identical to cells with no voltage applied (100.3 $\pm 1.2 \%$; Fig. $2 \mathrm{C})$. At $1 \mathrm{~V}$, there is an immediate shift to $0 \%$ of cells elongating. By examining voltages between 0.75 and $1 \mathrm{~V}$ more closely (Fig. 2D-F), we see a significant decrease in the fraction of cells undergoing elongation from $0.8 \mathrm{~V}(96.3 \pm 0.9 \%)$ to $0.85 \mathrm{~V}(57.3 \pm 5.0 \%)$ and $0.9 \mathrm{~V}(53.7 \pm 4.5 \%)$ then to $0.95 \mathrm{~V}(0 \%)$. This change in elongation is dependent on the frequency of the applied voltage with lower frequencies $(0.25$ and $0.50 \mathrm{~V})$ having a greater effect on elongation than higher frequencies $(0.75$ and $1.00 \mathrm{~V})$ at a given voltage (Supplementary Fig. S1A).

The number of cell divisions is also altered in response to an applied voltage (Fig. 3). At $0.75 \mathrm{~V}, 48.5 \pm 3.6 \%$ of cells do not divide during the $1 \mathrm{~h}$ period of observation, the number of divisions $=0$. The remainder of the cells undergo one $(34.2 \pm 1.1 \%)$ or two $(17.4 \pm 2.8 \%)$ divisions for the $1 \mathrm{~h}$ period. This distribution of divisions is identical to the control with no voltage applied. In comparison, at $0.9 \mathrm{~V}$ this distribution is reversed with the majority of cells not dividing $(89.6 \pm 2.1 \%)$ and only $10.4 \pm 2.1 \%$ undergoing one division. No cells were observed to divide more than once ( $\geq 2$ divisions $=0$ ). Staining with PI shows no disruption of the cell membrane after $1 \mathrm{~h}$ at both 0.75 and $0.9 \mathrm{~V}$ (Fig. 3B, C). As a positive PI control, cells were incubated at $100^{\circ} \mathrm{C}$ for $15 \mathrm{~min}$ 
A

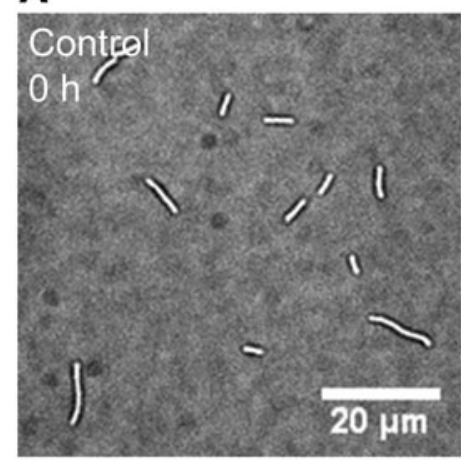

D

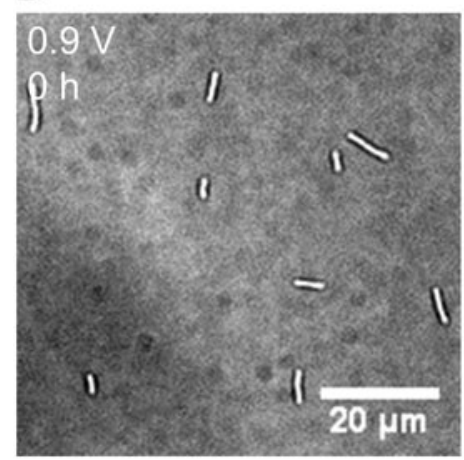

B

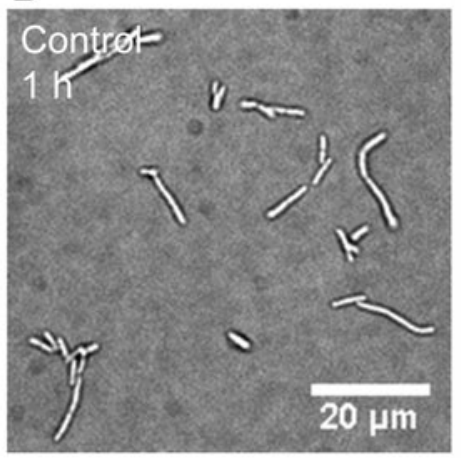

E

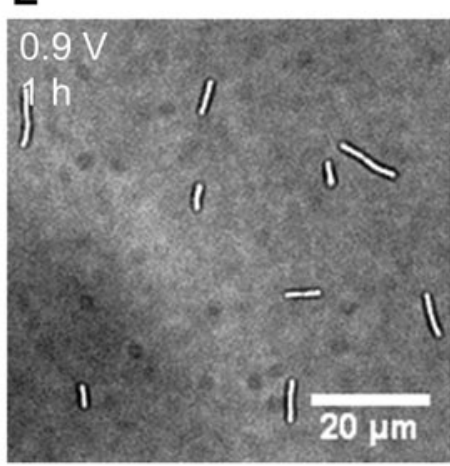

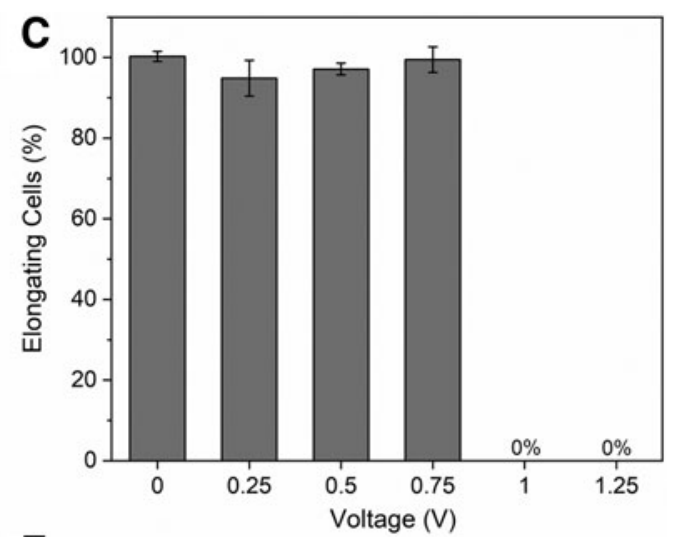

$\mathbf{F}$

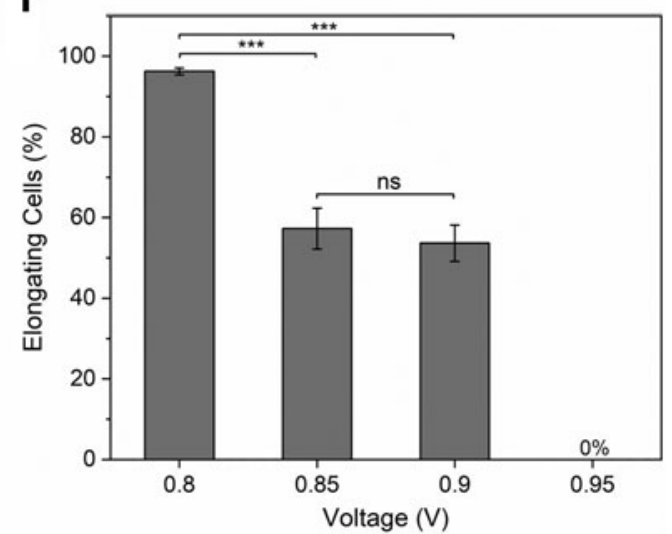

FIG. 2. Measurement of the fraction of cells undergoing elongation as a function of voltage. (A) Individual E. coli cells located between the two gold wires at $t=0$. (B) The same field of view after $1 \mathrm{~h}, 0 \mathrm{~V}$. (C) Measurement of elongation $(\geq 20 \%)$ for a $1 \mathrm{~h}$ period with an applied voltage. Each voltage is normalized against control cells located external to the wires, but on the same device. Three distinct experiments are carried out for each measurement and $\sim 100$ cells are analyzed for each experiment. The mean and standard deviation of the three experiments are shown. Significance was calculated using a chi-squared test of the pooled measurements. (D) Individual cells at $t=0$. (E) Same field of view after $1 \mathrm{~h}$ at $0.9 \mathrm{~V}$. (F) Measurement of elongation $(\geq 20 \%)$ for a $1 \mathrm{~h}$ period with an applied voltage. There was no significant difference between the percentage of elongating cells at 0.75 and $0.8 \mathrm{~V}$. $* * * p<0.001$, ns, nonsignificant.
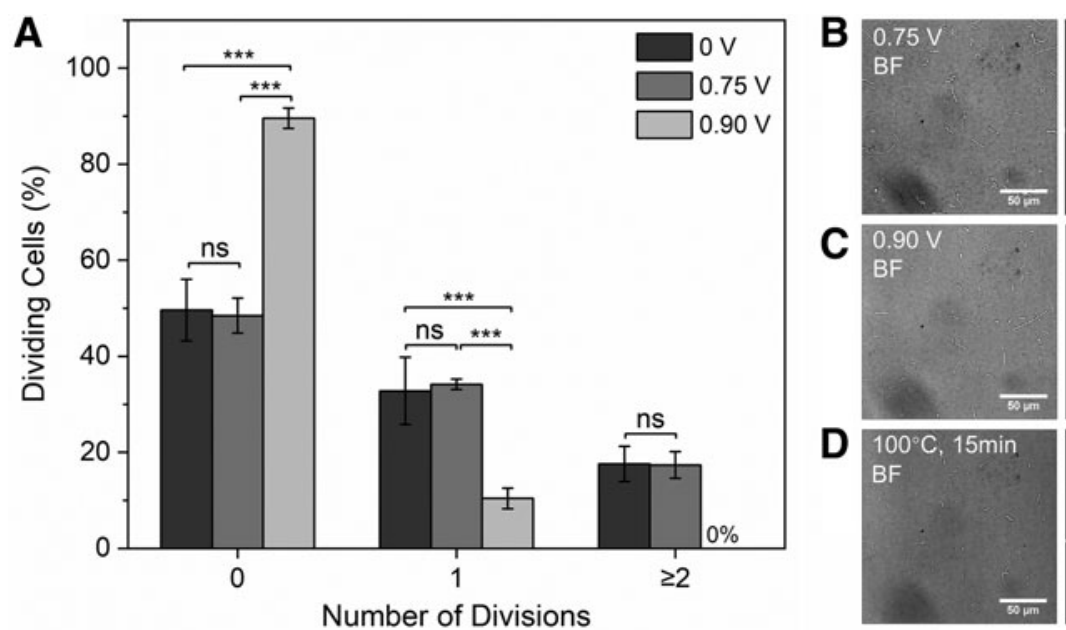

$0.75 \mathrm{~V}$ $\mathrm{Pl}$

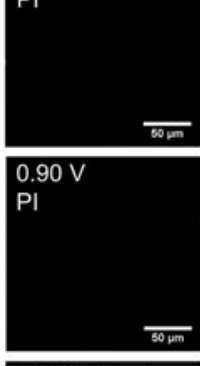

$100^{\circ} \mathrm{C}, 15 \mathrm{~min}$ Ri
FIG. 3. Measurement of cell division as a function of voltage. (A) Measurement of cell division for a $1 \mathrm{~h}$ period with an applied voltage $(0$, $0.75,0.9 \mathrm{~V})$. Three distinct experiments are carried out for each measurement and $\sim 100$ cell are analyzed for each experiment. The mean and standard deviation of the three experiments are shown. Significance was calculated using a chi-squared test of the pooled measurements. $* * * p<0.001$. (B, C) BF and fluorescence (PI) images of cells after $1 \mathrm{~h}$ at 0.70 and $0.90 \mathrm{~V}$, respectively. (D) As a positive PI control, cells were incubated at $100^{\circ} \mathrm{C}$ for 15 min. BF, brightfield; PI, propidium iodide. 
(Fig. 3D). As with elongation (Supplementary Fig. S1A), cell division is frequency dependent with an increased effect at lower frequencies (Supplementary Fig. S1B).

As a technical note, $1 \mathrm{~h}$ was selected as the time point for observation to provide sufficient time for cells to elongate and divide (Supplementary Fig. S2). A comparison of the fraction of cells undergoing elongation and division at $30 \mathrm{~min}$ and $1 \mathrm{~h}$ shows that elongation is slowed at $0.9 \mathrm{~V}$ with $10.0 \pm 4.2 \%$ of elongating cells increasing to $42.5 \pm 3.9 \%$ from $30 \mathrm{~min}$ to $1 \mathrm{~h}$, respectively. Similarly, the number of cell divisions increases with time. For example, at $30 \mathrm{~min}$ no cells are observed undergoing $\geq 2$ divisions at $0.75 \mathrm{~V}$, at $1 \mathrm{~h}$ $10.7 \pm 3.1 \%$ cells are observed to undergo $\geq 2$ division.

\section{Voltage-induced suppression of cellular growth}

The use of an applied voltage to limit, or slow, cell elongation and division (Figs. 2 and 3), but without disrupting the cell membrane (Fig. 3B, C), points toward an interesting voltage range $(\sim 0.8$ to $0.9 \mathrm{~V})$ that could be used for more subtle control of bacterial growth. We tested this by measuring elongation and division, as described earlier (Figs. 2 and 3), but with the addition of a "recovery" period after the voltage was applied (Fig. 4A). The first hour of the experiments was identical to conditions earlier (biphasic pulse, $0.5 \mathrm{~Hz}, 1 \mathrm{~h}$; voltage stated in text). This $1 \mathrm{~h}$ period is referred to as "voltage" in the figures. After $1 \mathrm{~h}$, no voltage is applied and cells are measured again after this $1 \mathrm{~h}$ "recovery" period.

After a $1 \mathrm{~h}$ recovery period (Fig. 4B), we see that the cells that had been subjected to $0.85 \mathrm{~V}(92.5 \pm 4.1 \%)$ or $0.90 \mathrm{~V}$ $(88.3 \pm 7.7 \%)$ elongate at only slightly decreased levels compared with that of $0.8 \mathrm{~V}(98.8 \pm 1.2 \%)$, which is identical to the control (Fig. 2). As observed after the $1 \mathrm{~h}$ of applied voltage (Fig. 2), $0.95 \mathrm{~V}$ is a threshold value with no elongation during or after the applied voltage. PI staining shows that $34 \%$ of these cells are positive for PI after the $1 \mathrm{~h}$ recovery period (Supplementary Fig. S3).

The number of cell divisions was also recorded (Fig. 4C and Supplementary Fig. S4), as described earlier (Fig. 3).
Data are shown for 0 cell divisions to highlight the recovery, data for each division is shown in Supplementary Figure S4. At $0.75 \mathrm{~V}$, approximately half of the cells do not divide while the voltage is applied $(48.5 \pm 3.6 \%)$, identical to a control at $0 \mathrm{~V}$ (Fig. 3A). Over the $1 \mathrm{~h}$ recovery, the number of cells that do not divide decreases to $15.2 \pm 4.5 \%$ with the remainder of cells undergoing $\geq 1$ divisions. At $0.8 \mathrm{~V}$, cell division partially recovers after the voltage is removed with $35.3 \pm 6.8 \%$ of cells not dividing, but with the other $65 \%$ of cells undergoing $\geq 1$ divisions. In comparison, at $0.85 \mathrm{~V}$, the cells do not recover with $86.2 \pm 7.2 \%$ cells not dividing while the voltage is applied and $76.5 \pm 13.1 \%$ not dividing during the recovery period. At $0.9 \mathrm{~V}$ no recovery effect was observed for cell division (data not shown).

\section{Mechanism of voltage-mediated control of bacterial elongation and division}

The use of an applied voltage to control bacterial elongation and division points toward membrane potential as an underlying cause of this response. To test this hypothesis, we used a membrane potential fluorophore, Rhodamine 123, to image cells while applying a voltage (Fig. 5). Rhodamine 123 is a "Nernstian" fluorophore that is released from cells during depolarization. ${ }^{28-31}$ Most recently, rhodamine dyes have been used with $E$. coli to understand the relationship between membrane potential and flagella rotation, probe the activity of a voltage-sensitive fluorescent protein, and test the use of conducting polymer wires. ${ }^{18,32,33}$

Bacteria were loaded with Rhodamine 123 using EDTA, as described in the section "Materials and Methods". A comparison of images recorded before and after $5 \mathrm{~min}$ with the applied voltage shows a decrease in Rhodamine 123 signal, averaged for 15 cells and compared with a control at $0 \mathrm{~V}$ $(99.0 \pm 7.0 \%)$. There is no significant difference between the decrease at $0.75 \mathrm{~V}(84.3 \pm 11.5 \%)$ and $0.90 \mathrm{~V}(80.6 \pm 8.2 \%)$. At $0.95 \mathrm{~V}$, a further decrease is observed $(76.4 \pm 7.0 \%)$. PBS supplemented with a high concentration of potassium $(600 \mathrm{mM}$; $\mathrm{pH} 7)$ was used as a positive control resulting in a decrease $(71.7 \pm 6.5 \%)$ under identical conditions.
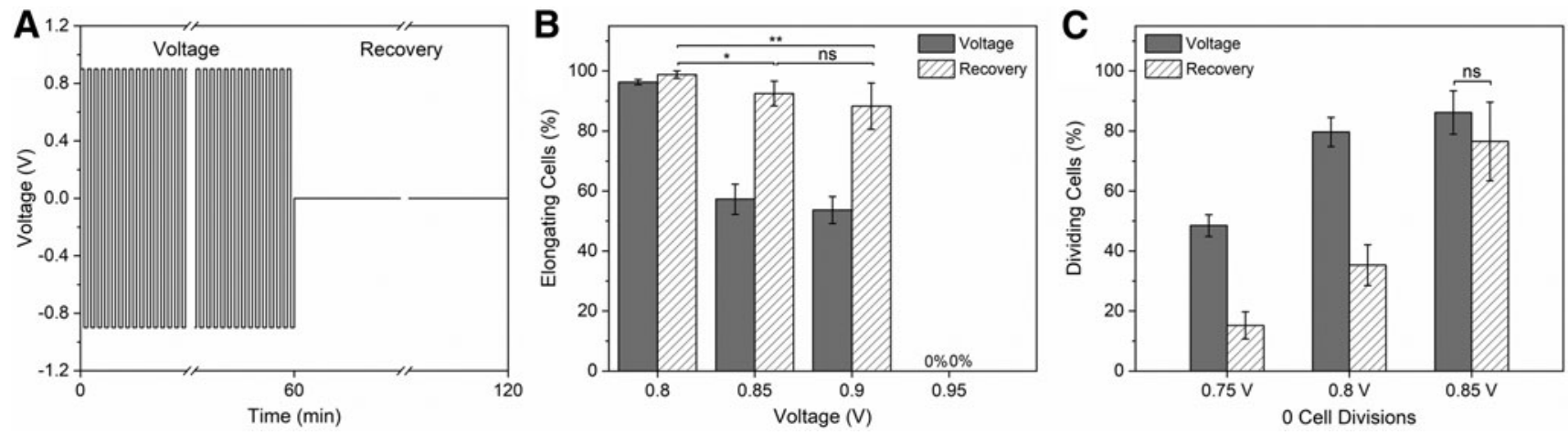

FIG. 4. Effect of a $1 \mathrm{~h}$ recovery period on cell elongation and division. (A) Schematic of applied voltage and recovery period. (B) Elongation before (solid gray) and after (stripes) the $1 \mathrm{~h}$ recovery period as a function of applied voltage. The voltage values are replotted from Figure $2 \mathrm{~F}$. (C) Cell division before (solid) and after (stripes) the $1 \mathrm{~h}$ recovery period as a function of applied voltage. The voltage values for $0.75 \mathrm{~V}$ are replotted from Figure $3 \mathrm{~A}$. Data for 1 and $\geq 2$ cell divisions are shown in Supplementary Figure S4. Three distinct experiments are carried out for each measurement and $\sim 100$ cells are analyzed for each experiment. The mean and standard deviation of the three experiments are shown. Significance was calculated using a chi-squared test of the pooled measurements. ${ }^{*} p<0.05,{ }^{*} * p<0.01$. 

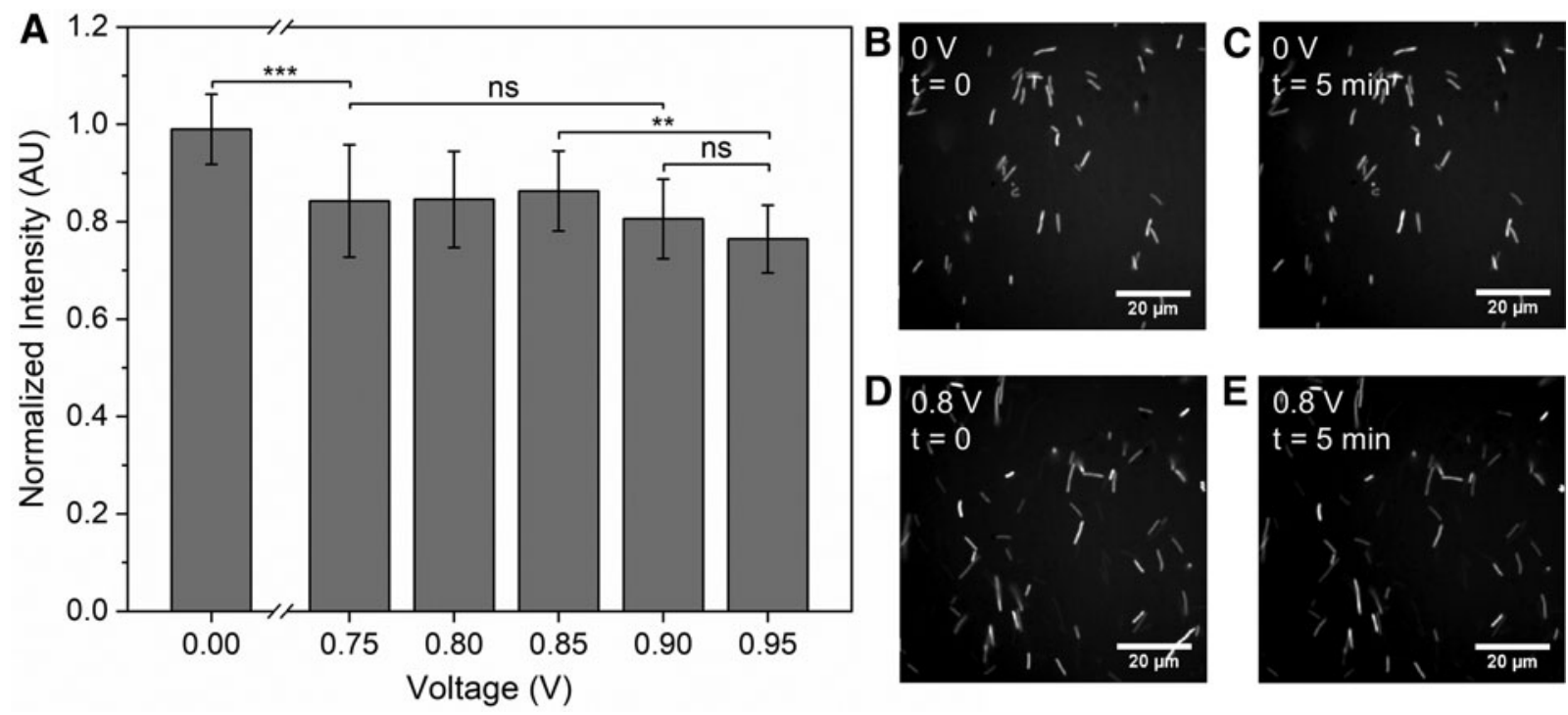

FIG. 5. Intracellular Rhodamine 123 fluorescence intensity as a function of applied voltage. (A) Average intensity of $n=15$ cells after 5 min with an applied voltage. Experiments were carried out in triplicate. Error bars show standard deviation. Values are compared with a control at $0 \mathrm{~V}$. One-way analysis of variance was used to compare multiple data sets and a $t$-test for voltage-to-voltage comparison. $* * * p<0.001, * * p<0.01$. (B, C) Representative fluorescence microscopy images of a control at $0 \mathrm{~V}$; at $t=0$ and $5 \mathrm{~min}$. $(\mathbf{D}, \mathbf{E})$ Representative fluorescence microscopy images at $0.8 \mathrm{~V}$; before $(t=0)$ and after $(t=5 \mathrm{~min})$ the applied voltage.

\section{Discussion}

The ability to image single cells while applying a voltage allows us to identify a voltage range where cell growth, measured as both the fraction of cells undergoing elongation and division, is suppressed, but not blocked. Imaging control cells, in the absence of a voltage, simultaneously on the same device removes any difference due to cell culture media or growth phase. ${ }^{23-26}$ The use of an applied voltage to inhibit bacterial growth is well known, ${ }^{1-6}$ but the ability to examine the cellular response on a single-cell level allows us to distinguish differences in the fraction of cells undergoing elongation and division as a function of voltage.

Cell division, compared with elongation, is more sensitive to an applied voltage. For example, during a $0.90 \mathrm{~V}$ pulse for $1 \mathrm{~h}, 53.7 \pm 4.5 \%$ of cells elongate (Fig. $2 \mathrm{D}-\mathrm{F}$ ), but division is essentially blocked ( 1 division $=10.4 \pm 2.1 \%$; $\geq 2$ divisions $=0$; Fig. 3A). At both voltages, the cell membrane is intact after the $1 \mathrm{~h}$ period based on a PI assay (Fig. 3B, C). This difference between elongation and division as a function of applied voltage may point toward the importance of the spatial localization of cell division proteins within the cell membrane, regulated by membrane potential. ${ }^{19,20}$

The range of voltages $(0.75-0.9 \mathrm{~V})$ with differential effects on cell elongation and division gives us a range to test for recovery after the voltage is removed (Fig. $4 \mathrm{~A}$ ). At $0.8 \mathrm{~V}$, we observe normal elongation during the $1 \mathrm{~h}$ of applied voltage $(96.3 \pm 0.9 \%)$ and recovery $(98.8 \pm 1.2 \%$, Fig. 4B), but cell division is suppressed while the voltage is applied (Fig. 4C). Although the majority of cells $(79.7 \pm 4.9 \%)$ do not divide while a $0.8 \mathrm{~V}$ voltage is applied, this value recovers when the voltage is removed with $28.1 \pm 7.1 \%$ and $36.6 \pm 7.3 \%$ undergoing 1 or $\geq 2$ divisions, respectively (Fig. 3A). A weaker trend is observed at 0.85 . At $0.9 \mathrm{~V}$, elongation recovers, but division does not.
Imaging cells loaded with Rhodamine 123 as a function of applied voltage suggests a change in membrane potential (Fig. 5) is at least partially responsible for the resulting changes in cell elongation and division. In comparison, a recent study has shown that an electric field leads to hyperpolarization of bacteria under normal conditions, with depolarization observed for inhibited, compared with proliferative, cells. ${ }^{17}$ Future study will determine if this difference is due to the differences in pulse parameters $(60 \mathrm{mV} / \mu \mathrm{m}, 0.1 \mathrm{kHz}, 2.5 \mathrm{~s})$ or a biological effect due to inhibited cells.

\section{Conclusion}

Electricity, in comparison with solution-phase antibiotics and ionophores, provides a spatially resolvable method to control the growth of bacteria. Our experiments show that small $(0.5 \mathrm{~V})$ changes in voltage alter the elongation and division of $E$. coli and that these changes can recover to control values when the voltage is removed. Beyond bacteria, all cells have a resting membrane potential that can be tuned with an applied voltage. It is hoped that the simple experimental setup used in these experiments will find use for others interested using live cell imaging as a function of membrane potential, ${ }^{34-36}$ and that the sensitivity of cells to voltage will inform both the developing fields of bacterial electrophysiology and mammalian electroceuticals.

\section{Authors' Contributions}

C.K.P., X.H., and B.R.F. designed the experiments and wrote the article. X.H. and B.R.F. performed the experiments and prepared the figures. 


\section{Acknowledgments}

The authors thank the BRAIN Initiative (NEI: 1R21EY026392) and the Pratt Fellows Program at Duke University for funding, Dr. Dhanya Jayaram for helpful discussion, and Prof. Michael Lynch for use of the incubated shaker.

\section{Disclaimer}

All coauthors have reviewed and approved of the article before submission. The article has been submitted solely to this journal and is not published, in press, or submitted elsewhere.

\section{Author Disclosure Statement}

No competing financial interests exist.

\section{Funding Information}

The authors thank the National Institutes of Health (NEI: 1R21EY026392) and Duke University's Pratt Fellows Program for support.

\section{Supplementary Material}

Supplementary Figure S1

Supplementary Figure S2

Supplementary Figure S3

Supplementary Figure S4

\section{References}

1. Sale A, Hamilton W. Effects of high electric fields on microorganisms: I. Killing of bacteria and yeasts. Biochim Biophys Acta Gen Subjects 1967;148:781-788.

2. Hamilton W, Sale A. Effects of high electric fields on microorganisms: II. Mechanism of action of the lethal effect. Biochim Biophys Acta Gen Subjects 1967;148:789800.

3. Hülsheger H, Potel J, Niemann E-G. Electric field effects on bacteria and yeast cells. Radiat Environ Biophys 1983; 22:149-162.

4. Grahl T, Märkl H. Killing of microorganisms by pulsed electric fields. Appl Microbiol Biotechnol 1996;45:148157.

5. Korem M, Goldberg N, Cahan A, et al. Clinically applicable irreversible electroporation for eradication of microorganisms. Lett Appl Microbiol 2018;67:15-21.

6. Costerton JW, Ellis B, Lam K, et al. Mechanism of electrical enhancement of efficacy of antibiotics in killing biofilm bacteria. Antimicrob Agents Chemother 1994;38: 2803-2809.

7. Fiedler S, Wirth R. Transformation of bacteria with plasmid DNA by electroporation. Anal Biochem 1988;170: 38-44.

8. Chassy BM, Mercenier A, Flickinger J. Transformation of bacteria by electroporation. Trends Biotechnol 1988;6:303309.

9. Delcour AH. Electrophysiology of bacteria. Ann Rev Microbiol 2013;67:179-197.

10. Benarroch JM, Asally M. The microbiologist's guide to membrane potential dynamics. Trends Microbiol 2020;28: 304-314.

11. Mathews J, Levin M. The body electric 2.0: Recent advances in developmental bioelectricity for regenerative and synthetic bioengineering. Curr Opin Biotechnol 2018;52: 134-144.

12. Levin M, Selberg J, Rolandi M. Endogenous bioelectrics in development, regeneration, and cancer: Drugs and bioelectronic devices as electroceuticals for regenerative medicine. iScience 2019;22:519-533.

13. Yang M, Brackenbury WJ. Membrane potential and cancer progression. Front Physiol 2013;4:1-10.

14. Chernet BT, Levin M. Transmembrane voltage potential is an essential cellular parameter for the detection and control of tumor development in a Xenopus model. Dis Models Mech 2013;6:595-607.

15. Rocha PR, Elghajiji A, Tosh D. Ultrasensitive system for electrophysiology of cancer cell populations: A review. Bioelectricity 2019;1:131-138.

16. Sirec T, Benarroch JM, Buffard P, et al. Electrical polarization enables integrative quality control during bacterial differentiation into spores. iScience 2019;16:378.

17. Stratford JP, Edwards CL, Ghanshyam MJ, et al. Electrically induced bacterial membrane-potential dynamics correspond to cellular proliferation capacity. Proc Natl Acad Sci U S A 2019;116:9552-9557.

18. Jayaram DT, Luo Q, Thourson SB, et al. Controlling the resting membrane potential of cells with conducting polymer microwires. Small 2017;13: [Epub ahead of print]; DOI: $10.1002 / \mathrm{smll} .201700789$.

19. Rajnicek AM, McCAIG CD, Gow N. Electric fields induce curved growth of Enterobacter cloacae, Escherichia coli, and Bacillus subtilis cells: Implications for mechanisms of galvanotropism and bacterial growth. J Bacteriol 1994;176: 702-713.

20. Strahl H, Hamoen LW. Membrane potential is important for bacterial cell division. Proc Natl Acad Sci U S A 2010; 107:12281-12286.

21. Rojas ER, Huang KC, Theriot JA. Homeostatic cell growth is accomplished mechanically through membrane tension inhibition of cell-wall synthesis. Cell Syst 2017;5:578590.e6.

22. Rojas ER, Huang KC. Regulation of microbial growth by turgor pressure. Curr Opin Microbiol 2018;42: 62-70.

23. Pareilleux A, Sicard N. Lethal effects of electric current on Escherichia coli. Appl Environ Microbiol 1970;19:421424.

24. Rosenberg B, Van Camp L, Krigas T. Inhibition of cell division in Escherichia coli by electrolysis products from a platinum electrode. Nature 1965;205:698-699.

25. Rowley BA. Electrical current effects on E. coil growth rates. Exp Biol Med 1972;139:929-934.

26. Spadaro J, Berger T, Barranco S, et al. Antibacterial effects of silver electrodes with weak direct current. Antimicrob Agents Chemother 1974;6:637-642.

27. Schneider CA, Rasband WS, Eliceiri KW. NIH image to ImageJ: 25 Years of image analysis. Nat Methods 2012;9: 671.

28. Diaper J, Tither K, Edwards C. Rapid assessment of bacterial viability by flow cytometry. Appl Microbiol Biotechnol 1992;38:268-272.

29. Kaprelyants A, Kell D. Rapid assessment of bacterial viability and vitality by rhodamine 123 and flow cytometry. J Appl Bacteriol 1992;72:410-422.

30. Resnick M, Schuldiner S, Bercovier H. Bacterial membrane potential analyzed by spectrofluorocytometry. Curr Microbiol 1985;12:183-185. 
31. Matsuyama T. Staining of living bacteria with rhodamine 123. FEMS Microbiol Lett 1984;21:153-157.

32. Kralj JM, Hochbaum DR, Douglass AD, et al. Electrical spiking in Escherichia coli probed with a fluorescent voltage-indicating protein. Science 2011;333:345-348.

33. Lo C-J, Leake MC, Pilizota T, et al. Nonequivalence of membrane voltage and ion-gradient as driving forces for the bacterial flagellar motor at low load. Biophys J 2007; 93:294-302.

34. Park J, Kuo Y, Li J, et al. Improved surface functionalization and characterization of membrane targeted semiconductor voltage nanosensors. J Phys Chem Lett 2019: 3906-3913.

35. Kuo Y, Li J, Michalet X, et al. Characterizing the quantumconfined stark effect in semiconductor quantum dots and nanorods for single-molecule electrophysiology. ACS Photonics 2018;5:4788-4800.

36. Park K, Weiss S. Design rules for membrane-embedded voltage-sensing nanoparticles. Biophys J 2017;112:703713.

Address correspondence to: Christine K. Payne, PhD Department of Mechanical Engineering and Materials Science Duke University Durham, NC 27708

USA

Email: christine.payne@duke.edu 